\title{
AN INTRODUCTION ON LITERATURE OF SMART CITY
}

\author{
Sina Haji Hosseinloo \\ Department of Urbanism Engineering, Tabriz Branch, Islamic Azad University, Tabriz, \\ Iran
}

\begin{abstract}
The city is the economic and social life, as in the range of human abode, food and so on. The heights of the dependence of man, his various powers of the time to have done, and by the desire to consolidate and bring to the life of the necessary coordination with the villages thereof, and in the nature of necessity and for a dwelling-place and information to build the human environment. In all, according to the nature of the species, and the culture and civilization of the difference, and principal users, as one element in the human city, and that the beneficiaries of the effective element of his own. Unfortunately, irregular to pass out to the cities, especially the metropolises made us to increase of faces, to provide the service, and to the many questions of the citizens. Smart of this question in recent decades, a number of strategies for the solution of the great circles that was offered in the academic plans. That is powerful, smart electronic city and citizens of continuous service users, but unlike electronic city so residents know each client, users smart and play the role of the citizens of the city, the head of the fountain. Unlike the electronic city, only to meet the needs of the citizens of the city had no pain, but in the interaction cycle, is exposed to the knowledge of the heads of men, and were out of the city, provide services in the city, which is done in the way of life of the urban development. On the other hand, it should be noted, because of the large and the density of the high places of the cities of the time, already in the cities which have no matter to work on the administration of the traditional methods of the town is rather moderate. This study tries to explain the history of the electronic city, he laid the city: and the sorrow of mourning in the city. In this study, we found an expert to other learned men proceeded so far, better to use.
\end{abstract}

\section{KEYWORDS}

City, Smart city, Smart Architecture

\section{INTRODUCTION}

Increased by the growth of the city in the city, which emerged from Africa, Smart, hardware and software in order to supply the needs of the men of the city the new features in the knowledge of life. What moves us to the use of the conscious, however, of the city, into the city, not only to improve the level of the price of the use of electronic means of communication for the means of the citizens of the city. Elements 6, which is not smart because sorrow, the pain, the pain of the people, his government, himself, the pain and suffering of life. Varmusurndim six elements includes it the city of the economic pain, the pain of the people, his government, himself, the pain and suffering of life. Make ready the pain the pain of the people, the city seems to be necessary to the process of virtualization these two steps to the very end of their empire. A prudent man level of education includes, from the doctrine of the, research, and the heads of men, and a new level of development it has in him, and spared no expense in the public administration, access to the 
websites of the public online services, transparent government, and to promote the popularity-e, and the renewing of nib. Increased by the growth of the city has emerged from Africa For a smart in the city of hardware and software, and in the life of the citizens, for the purpose of relieving the needs of the knowledge of the city a new look. Each component is opening a new reason for pain in the Urbanism. What moves us to the use of the conscious, however, of the city, into the city, not only to improve the level of the price of the use of electronic means of communication for the means of the citizens of the city. The council of the pain out of the cities to be a conscious effort to use information technology, you need to be transformed in our area, and increasing in danger indeed, but the ways of the ways. It is not the use of reason, and the city: and digital the pain of the city. Label has described the smart city is able to learn the skills, the development of technological innovation. In this way it is not necessary for every city dolor, Laconia, but the pain of the city.

\section{SMART CITY}

The term "smart" a lot of attention of late 1990 had recently been begun in the city of cities, and to pain in the health of many cities with the Commission of the European smart Agenda, to matures eliteas it acts in the alliance was concluded with the drive. The concept of a different nature, and he took the city: his work is a further short period the city of pure marketing plan to use. (ZeynaliAzim, Aghajani, 2014).The most effective definition of an smart city is a community that is efficient, viable and sustainable, and these three elements go hand in hand. Traditionally, the water, gas, electricity, transport, emergency, building, hospitals and public-law systems of a city are separated and work independently in silos. A truly efficient city requires not only the performance of each system to be optimized but also that these systems are managed in an integrated manner to prioritize investments and maximize value (Aoun, 2013). "Smart City" (Partridge, 2004) refers to a city in which ICT strengthen freedom of speech and access to public information and public services. The approach of smart city was originally applied. This approach has created a network of cities (Partridge, 2004). Based on our literature research in this field, we believe that urban performance should be measured in providing the most comprehensive definition of smart cities against the hard infrastructure of the city and its attention to the environment; Accessibility and use of information and communication technologies (ICT) for the urban population as well as for public administration (Graham, Marvin, 1996, Roller, Waverman, 2001); And the generation of localized knowledge spillovers (LKS), which come from a direct contact between colleagues in an urban environment (Breschi, Lissoni , 2001, Fu, 2007, Capello, 2009). In addition, the smart city should be measured through its participative governance, its smart economy, its smart urban mobility, its smart environmental strategy and the management of natural resources and the presence of its self-determined, independent and conscious citizens (Roch, 2012).Actors formatting the final document allowed.

\section{ELEMENTS OF A SMART CITY}

Smart Cities is expected to dramatically improve the quality of life of its citizens, promote investment and create a sustainable urban environment (Vasseur\&Dunkels, 2010). Interestingly, while the term Smart City literarily implies a result or result, most use the term consider it as an "activator" of change by exploring the relevant open innovation processes (Paskaleva, 2011). Other concepts such as (Nam, Taewoo, Pardo, 2011) consider intelligent urban as urban innovation with technological, organizational and political innovations. Finally, an intelligent city 
could be understood as a certain intellectual capacity that addresses several innovative socioeconomic and socioeconomic aspects of growth (Zygiaris, 2012). Three elements that characterize the Smart City concept (Hollands, 2008) include:

- use of networked infrastructures to improve economic and political efficiency as well as to promote social, cultural and urban development; Infrastructure, including ICT;

- Business-led urban development and

- Social and environmental sustainability.

Social sustainability means social cohesion and a sense of belonging, while environmental sustainability refers to the environmental and "green" implications of urban growth and development. (Komninos, 2011) presents the concept of the spatial intelligence of the cities as a composite capacity, which enables the municipalities in the city to use the intellectual capital, the institutions and the material infrastructure in dealing with problems and challenges. The spatial intelligence consists of three kinds of intelligence: 1) the creativity, the creativity and the intellectual capital of the city; 2) the collective intelligence of the institutions and the social capital of the city; 3) the artificial intelligence of public and urban intelligent infrastructure, virtual environments and intelligent agents. These three types of intelligence cover all dimensions of the city and map on three types of spaces - physical, institutional, and digital spaces. The "physical space" corresponds to the richness and creativity of the city, the "institutional space" encompasses the social capital and the collective intelligence of a city population, and the "digital space" contains the artificial intelligence embedded in the physical environment Digital technologies. (Vasseur\&Dunkels, 2010) identified the following infrastructure networks for smart cities (Ojo et al., 2014). Some of these networks concern transport, public safety, public services, utilities and social networks. In physical space, skills and human capital are considered the most important element. For example, it is claimed that the greatest competitive advantages of cities are qualities that attract the best and brightest from around the world to a city (Bloomberg, 2011). This is supported by the fact that educated cities are growing faster than the less educated, as qualified cities are more productive in economic terms and better adapted to economic shocks (Glaeser\&Saiz, 2003). We summarize the various elements of Smart's definitions (Carmen et al., 2009) and (Nam, Taewoo, Pardo, 2011).

\section{SMART CITY MODEL}

It begins with the concept of a primordial system, which can be understood as an umbrella for a process in any of the above-mentioned networks of systems. Such urban systems may be elementary units or complex units of simpler units. We then introduce the Urban Information Model to structure and classify the many different types of information contained or flowing in these networks. From an information technology perspective, it is helpful to consider the Urban Information Model as a very large number of layers representing a common two-dimensional space, the urban environment, whether it is a single city or a metropolis. This urban information model is presented in a highly simplified form in Figure 1. Such a model is often instituted in a Geographical Information System (GIS), but increasingly social network tools are taking this model in new directions. The groups of layers are:

A. The natural environmental group including topography, flora and fauna, natural resources, geology, and so on. B. The infrastructure group including built environment (roads, bridges, tunnels, buildings, pipelines, electrical and communications lines and so on) as well as things that 
move (trains, boats, buses, etc.) that are built on the Natural Is environment. C. The resource group which represents the materials which originate and ultimately return to the natural environment after they have passed through different processes of refining and consumption in the services group, as well as capacities which are temporarily consumed, for example by the Pass a vehicle over a bridge and then re-create. D. The services group, which provide many kinds of services, including transportation, energy, trade, health care, and so on. Many of these services consume or transform resources from the resource group. That is, The Social Systems Group, including the sites and actions of people, such as trade and culture, laws, regulations, governance, and so on, to use the services and resources from these groups. This group contains the top and most interesting layer in which we find the People Systems. (Harrison C, Donnelly A, 2011).

Figure 1: A simplified representation of the Urban Information Model. Each plane represents a group of layers that contain different but related types of information about the two-dimensional space.

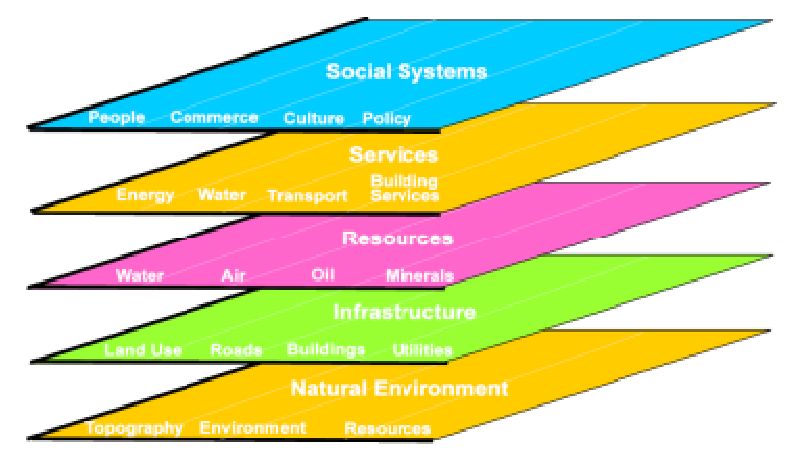

\section{FEATURES SMART CITY}

It is a mistake to believe that smarter cities require more investment in IT information technologies) - what cities need to do is use IT as a means to achieve the objectives and objectives of local (and national and EU) levels. The main issue that makes cities more smart is not the development of appropriate technologies as such, but addressing the challenges of changing organizations and existing working methods to use these new technologies to deliver smarter cities. The concept of smart cities has also been used in different ways: to describe a cluster of innovative organizations within a region; The presence of industries with a strong focus on ICT; Business parks; The actual level of education of the inhabitants of a given city; The use of modern technologies in an urban context; Technological resources that increase the efficiency and effectiveness of the government; Etc. A clear definition remains unclear (Giffinger R, 2007). In the literature the term Smart City is referred to the relation between city administration and city administration. Smart City is also used to discuss the use of modern technologies in urban everyday life. This includes not only ICT, but also modern transport technologies. Logistics as well as new transport systems as "smart" systems, which improve the urban traffic and the mobility of the inhabitants.

In addition, various aspects of life in a city related to the term smart city such as security / safe, green, efficient $\&$ sustainable, energy etc. are mentioned. In summary, there are several fields of action described in the literature. The term smart city: industry, education, participation, technical infrastructure, various "soft factors"; (See Figure 2, Table 1) as the umbrella for the further development of smart cities that should include the findings, as well as the inclusion of additional factors. (Correia et al., 2011). Thus, the key features of the smart city are intelligent scientific 
communities of smart people and (Anthopoulos, Vakali, 2011) territorial institutions using the ecologically smart urban infrastructure, smart and controlled by a single smart city management platform, the foundation of Urban Internet Systems, services, knowledge and citizens (Abdoullaev, 2011).

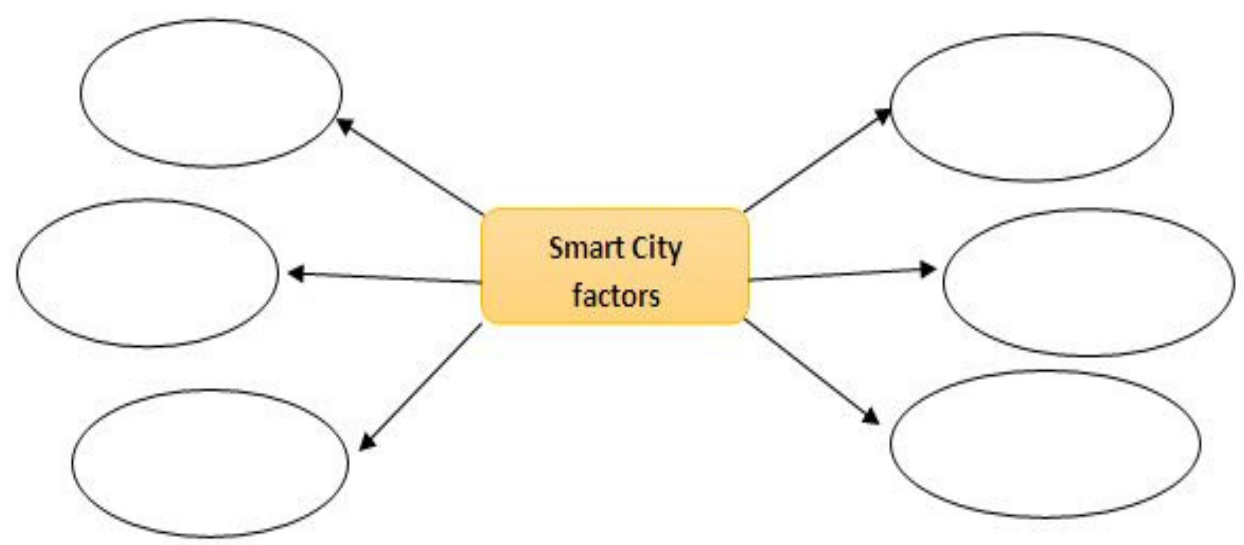

Figure 2: Characteristics and factors of a smart city

Table 1: Characteristics and factors of a smart city

\begin{tabular}{|c|c|}
\hline \multicolumn{2}{|c|}{ Characteristics smart city } \\
\hline Smart Economy & 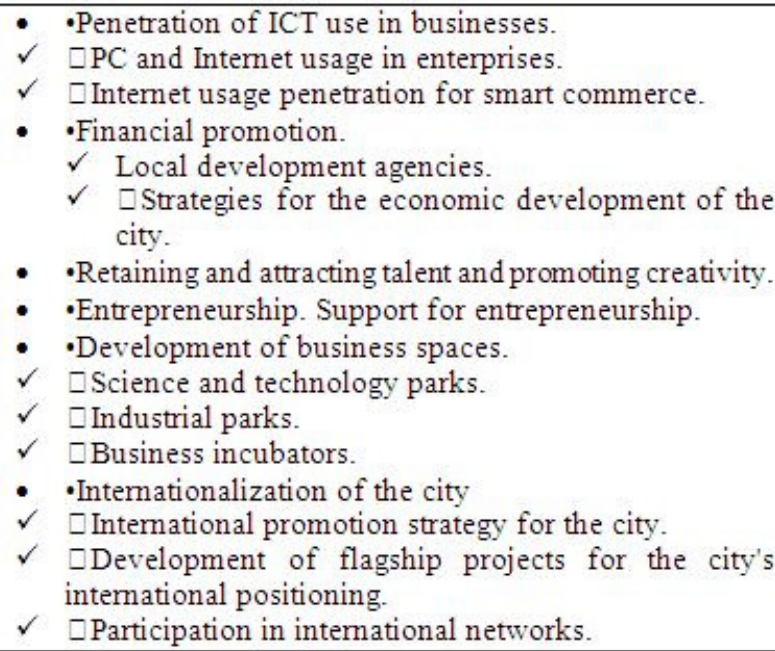 \\
\hline Smart people & $\begin{array}{ll} & \text {-Education and training. } \\
\checkmark & \square \text { Population with college degrees. } \\
\checkmark & \square \text { Presence of a University in the City. } \\
\checkmark & \square \text { Priority areas for educational offers. } \\
\checkmark & \square \text { Adaptation of the educational offer to the current lab } \\
& \text { ourmarket demand. } \\
\text { - } & \text {-S-Learning. } \\
\checkmark & \square \text { Plans for smart development in classrooms. } \\
\checkmark & \square \text { Penetration of ICT use in education. } \\
\checkmark & \square \text { Implementation of e-learning programmes. } \\
\checkmark & \square \text { Life-long training. } \\
\text { - } & \text {-Human Capital } \\
\checkmark & \square \text { Collaboration between companies and knowledge } \\
\text { centers. }\end{array}$ \\
\hline
\end{tabular}




\begin{tabular}{|c|c|}
\hline Smart Governance & $\begin{array}{l}\text { - Local public spending on ICT. } \\
\text { - Website availability. } \\
\text { - Strategic plans to promote e-Government and ICT } \\
\text { - On-line public services. } \\
\checkmark \text { Percentage of services available on-line. } \\
\checkmark \text { Major on-line services offered by cities. } \\
\checkmark \text { Administration staff that use Internet-comnected } \\
\text { - computers. } \\
\text { - Electronic signature. } \\
\text { - Transparent governance. } \\
\checkmark \text { Citizen participation. } \\
\checkmark \text { Electronic voting. } \\
\text { - Promoting ICT and Innovation }\end{array}$ \\
\hline Smart Mobility & $\begin{array}{l}\text { - Comnectivity and ICT infrastructure. } \\
\checkmark \text { Penetration of ICT use in homes. } \\
\checkmark \text { Internet usage. } \\
\checkmark \text { Broadband coverage. } \\
\checkmark \text { Broadband usage. } \\
\checkmark \text { Mobile phone usage. } \\
\checkmark \text { Mobile Internet usage penetration. } \\
\text { - Public Internet Access. } \\
\checkmark \text { Wi-Fi hotspots in cities. } \\
\checkmark \text { Public Internet access centers. } \\
\checkmark \text { Promotion deals with ISPs. }\end{array}$ \\
\hline Smart Environment & $\begin{array}{l}\text { - Security and trust. } \\
\checkmark \text { Using ICT to improve public safety. } \\
\text { - Culture and identity. } \\
\checkmark \text { Initiatives for the digitization of heritage assets }\end{array}$ \\
\hline Smart Living & $\begin{array}{l}\text { - s-Health. } \\
\checkmark \text { Electronic health card. } \\
\checkmark \text { On-line medical services. } \\
\checkmark \text { Remote home control or alarm systems for patients. } \\
\text { - Accessibility and e-Inclusion. } \\
\checkmark \text { Development of digital inclusion programmers for } \\
\text { groups at risk of exclusion. }\end{array}$ \\
\hline
\end{tabular}




\section{SMART CITY ARCHITECTURE}

The concept of "Smart City" has evolved over time. At least four different descriptions of what is a smart city can be found in the literature and practice, which mainly include innovation, SMART growth, community rooms; namely:

- Virtual reconstruction of cities, SMART representations, simulation cities or virtual cities.

- Smart cities, urban development based on information and communication technologies.

- Urban environments with embedded information and communication technologies that create interactive spaces that bring the calculation to the physical world. Smart cities (or smart spaces more general) refer to physical environments where information and communication technologies and sensor systems disappear as they are embedded in physical objects and the environment in which we live, travel, and work.

- Territories that bring innovation systems and ICT to one and the same place by combining the creativity of talented people forming the urban population, facilities that promote learning and innovation, and smart innovation spaces that enable innovation and knowledge management.

His closest synonyms are "Innovation city", "smart communities" and "smart innovation environments". Smart cities and regions are for us areas with a high level of learning and innovation that integrate the creativity of their population, their knowledge facilities and their smart infrastructure for communication and knowledge management. The characteristic feature of intelligent cities is their increased performance in the field of innovation, as innovation and the solution of new problems are characteristic features of intelligence. In this sense, smart cities and regions represent advanced territorial innovation systems that facilitate the institutional mechanisms of knowledge creation and application through smart spaces and online tools for communication and knowledge management. (Abdoullaev, 2011) The concept of smart city has also been classified as part of the broader notion of Smart City (Anthopoulos, Tsoukalas, 2006) of where a generic multi-tiered architecture was introduced for smart cities, and Smart City Software and services layer. This generic architecture (Figure 3) contains the following layers:

- User level that affects all e-service end users and the stakeholders of ansmart city. This layer appears both at the apex and at the bottom of the generic architecture as they look after both the local stakeholders that care for the smart city as well as the e-services and end users who use the smart city to "consume" services and participatedialogue and decision-making.

- Service layer, which includes all e-services offered by smart city.

- Infrastructure layer that includes network, information systems and other facilities that contribute to s-service delivery.

- Data layer containing all information needed, produced and collected in the smart city.

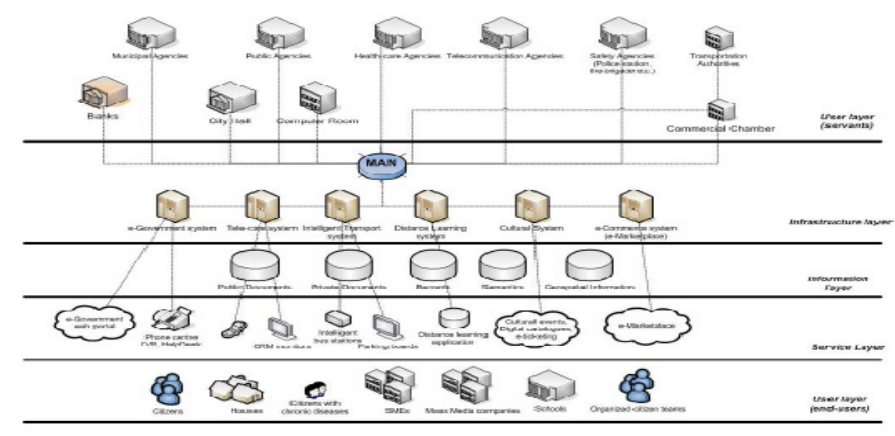

Figure 3: Smart cities layered architecture 


\section{CONCLUSION}

Today, the development of cities, pollution and related problems has led city officials and intellectuals to solve the urban problems through intelligent city strategy. Smart City is a city has a proper communications infrastructure, hardware, software, organization and human resources. The smart city is able to deliver services that are produced by governmental institutions, institutions, organizations, businesses, stores and other private sectors of a city in twenty-four hours a day, continuously and securely for its citizens. The city is made up of citizens, transport, environment, infrastructure and overall smart and education living in the use of advanced technologies. In such a city, the geographic features do not disappear, but intelligent processes such as warp and shot of a network connection through currents and signals connect urban locations and functions. In such a city informative not only led to isolation of the location citizens, but also on the contrary, places and families are formed in a wise space and have the possibility of communication, exchange of ideas and more services. In this city, urban managers with knowledge of departments and help of intelligent tools have better facilities for smart management of departments and areas they are responsible for. The smart city plan is a deliberate effort to use information technology to change life and work in our area in critical ways, rather than increase the path. Smart City label is usually used to describe a city is able to support learning techniques, technology development and innovation. In this sense, every digital city is not necessarily smart, but every smart city has digital components. Comments on the relationship between the real and the virtual city are different. while smart city encompasses functions of research, technology transfer, product development and technology innovation as a context for innovative industries such as the city of knowledge.

\section{REFERENCES}

1. Aoun C, (2013). The Smart City Cornerstone: Urban Efficiency, Schneider Electric White Paper Revision 0, 1-13.

2. Partridge, H., (2004). Developing a Human Perspective to the Digital Divide in the Smart City. In: "ALIA 2004, challenging ideas", Queensland University of Technology Brisbane, Australia, 2004.

3. Berry, C.R., and Glaeser, E.L., (2005), The Divergence of Human Capital Levels Across Cities, Papers in Regional Science, 84 (3): 407-444.

4. Breschi, S. and Lissoni, F., (2001), Localized Knowledge Spillovers vs. Innovative Milieux: Knowledge 'Tacitness' Reconsidered, Papers in Regional Science, 80(3): 255-273.

5. Capello, R., (2009), Spatial Spillovers and Regional Growth: A Cognitive Approach, European Planning Studies, 17(5): 639-658.

6. Florida, R.L., (2002), The Rise of The Creative Class and How It's Transforming Work, Leisure, Community and Everyday Life, New York: Basic Books.

7. Fu, S., (2007), Smart Cafe' Cities: Testing Human Capital Externalities in the Boston Metropolitan Area, Journal of Urban Economics, 61 (1): 87-111.

8. Glaeser, E.L., and Berry, C.R., (2006), Why Are Smart Places Getting Smarter? Taubman Center Policy Brief 2006-2, Cambridge, MA: John F. Kennedy Schoolof Government.

9. Graham, S., and Marvin, S., (1996), Telecommunications and the City: Electronic Spaces, Urban Place, London: Routledge.

10. Roller, L.H., and Waverman, L., (2001), Telecommunications Infrastructure and Economic Development: A Simultaneous Approach", American Economic Review, 91(4): 909-923.

11. Roche St, Nabian N, Kloeckl N and Ratti C. (2012). Are 'Smart Cities' Smart Enough? We live in the Global Location Age. "Where am I?" is being replaced by, "Where am I in relation to everything else?" Introduction of Penn State Geospatial Revolution Project: 215-235 (http://geospatialrevolution.psu.edu/). 
12. Bloomberg, M. R. (2011). The Best and the Brightest - New York City's bid to attract science talent could serve as a model for other cities. Scientific American, 305(3), 11.

13. Giffinger, R., Fertner, C., Kramar, H., Kalasek, R., Pichler-Milanović, N., \&Meijers, E. (2007). Smart cities Ranking of European medium-sized cities. October: 1-28.

14. Glaeser, E. L., \&Saiz, A. (2003). The Rise of the Skilled City (No. No 25). Social Science Research. Cambridge, Massachusetts.

15. Hollands, R. G. (2008). Will the real smartcity please stand up? Intelligent, progressive or entrepreneurial. City: Analysis of Urban Trrends, Culture, Theory, Policy and Action, 12(March 2012), 37-41.doi:10.1080/13604810802479126

16. Nam, T., \&Pardo, T. (2011). Conceptualizing Smart City with Dimensions of Technology, People and Institutions.In The Proceedings iof the 12th Annual Conference on Dogital Government Research (pp. 282 - 291). MD, USA: ACM Press.

17. Paskaleva, K. A. (2011). The smart city: A nexus for open the smart city: A nexus for open innovation? Buildings, 3(March 2012), 153-171. doi:10.1080/17508975.2011.586672.

18. Vasseur, J.-P., \&Dunkels, A. (2010). Smart Cities and Urban Networks. In Interconnecting Smart Objects with IP The Next Internet (335-351). Morgan Kaufmann. doi:10.1016/B978-0-12375165-2.00022-3.

19. Zygiaris, S. (2012). Smart City Reference Model: Assisting Planners to Conceptualize the Building of Smart City Innovation Ecosystems. Journal of the Knowledge Economy.doi: 10.1007/s13132-012-0089-4.

20. Ojo A, Curry E and Janowski T. (2014). DESIGNING NEXT GENERATION SMART CITY INITIATIVES - HARNESSING FINDINGS AND LESSONS FROM A STUDY OF TEN SMART CITY PROGRAMS, Twenty Second European Conference on Information Systems, (Tel Aviv 2014). 1-14.

21. Harrison C, Donnelly A (2011).A Theory of Smart Cities Proceedings of the 55th Annual Meeting of the ISSS - 2011, Hull, UK. 1- 15.

22. Giffinger R, (2007). Smart cities Ranking of European medium-sized cities, Centre of Regional Science, Vienna UT, October 2007, 1-28.

23. Correia, L M, Wünstel K and Lucent A (2011). Smart Cities Applications and Requirements, Net!Works European Technology Platform Expert Working Group.

24. Abdoullaev A, (2011). Keynote: "A Smart World: A Development Model for Intelligent Cities", The 11th IEEE International Conference on Computer and Information Technology. 1-28.

25. Anthopoulos LG, Vakali A, (2011). Urban Planning and Smart Cities: Interrelations and Reciprocities, Springer-Verlag Berlin Heidelberg, adfa. 1-12.

26. Anthopoulos, L., Tsoukalas, I. A. (2006). The implementation model of a Digital City. The case study of the first Digital City in Greece: e-Trikala. Journal of e-Government (Haworth Press, Inc.), Vol.2 (2).

27. ZeynaliAzim A, Aghajani R, (2014). Designing Smart Cities, Indian Journal of Fundamental and Applied Life Sciences, Vol. 4 (S3).146-153.www.cibtech.org/sp.ed/jls/2014/03/jls.htm.

28. Caragliu A., De Bo C., Nijcamp P. (2009), "Smart city in Europe", 3rd Central European

29. Hall P. (2000), "Creative cities and economic development", Urban Studies, Volume 37, Issue 4, pp. 633-649.

30. Dameri R.P. (2013), "Searching for Smart City definition: a comprehensive proposal", International Journal of Computers \& Technology, Volume 11, Issue 5.

31. Ishida T. (2002): "Digital City of Kyoto", Magazine Communications of the ACM - How the virtual inspires the real, Volume 45, Issue 7, pp. 76-81, ACM New York, NY, USA.

32. Giffinger R. (2007), Smart Cities: Ranking of European medium-sized cities, Centre of Regional Science, Vienna.

33. Su K., Li J., Fu H. (2011), "Smart City and the applications", IEEE International Conference on Electronics, Communications and Control (ICECC), pp. 1028-1031.

34. Setis-Eu(2012), setis.ec.europa.eu/implementation/technology-roadmap

35. Qi L. and Shaofu L. (2001), "Research on Digital City Framework Architecture", IEEE International Conferences on Info-Tech and Info-Net, Volume 1, pp. 30-36. 
Civil Engineering and Urban Planning: An International Journal (CiVEJ ) Vol.3, No.4, December 2016

36. Schuler D. (2002), "Digital Cities and Digital Citizens", Digital Cities II: Computational and Sociological Approaches, Springer LNCS, Volume 2362, pp. 71-85.

37. Komninos N. (2008), "Intelligent Cities and Globalization of Innovation Networks", Routledge, London.

\section{Author:}

Sina Haji Hoessinloo, Iran

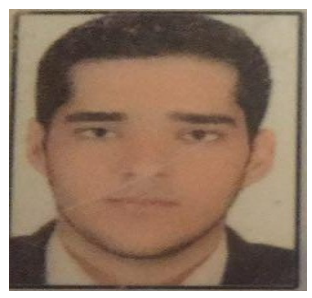

